\title{
KNOWLEDGE OF COMMONLY PRESCRIBED MEDICATIONS TO OCTOGENARIANS
}

\author{
T.V.N. Didone ${ }^{1}$, D. Oliveira de Melo' ${ }^{2}$ E. Ribeiro ${ }^{1,3}$
}

\begin{abstract}
Eighty outpatients aged 80 years or more were face-to-face interviewed in order to assess the appropriate recall of six items of information about the 19 most commonly prescribed medications by means of a questionnaire cross-culturally adapted into Brazilian Portuguese. In some cases, the caregiver was interviewed instead. The frequency of medications whose information was appropriately recalled ranged from $36 \%$ to $100 \%, 36 \%$ to $100 \%, 18 \%$ to $90 \%, 9 \%$ to $63 \%, 0$ to $25 \%$, and 0 to $10 \%$ for respectively the following items dosage, form of administration, indication, storage, side effects, and precautions and warnings, indicating poor overall knowledge. The lowest frequency of dosage and form of administration was seen for alendronic acid (36\% each), and the highest frequency of side effects was found for donepezil (25\%). Octagenarians and their caregivers should be constantly counseled on medication information.
\end{abstract}

Key words: Aged, 80 and over, drug storage, health knowledge, attitudes, practice, patient education as topic, patient medication knowledge.

\section{Introduction}

The world's population is ageing with the feature that the number of people aged $\geq 80$ years is growing even faster than the number of older people overall (1). By 2035, the number of octogenarians in Brazil will double, rising from the current $2.0 \%$ to $3.8 \%$ of the population (2). Older individuals use more drugs (1) and have less knowledge of them $(3,4)$ in comparison to younger people. Among the elderly, octogenarians may have still even less medication knowledge. Primary care patients aged $\geq 80$ years presented $53 \%$ less chance of appropriately recall the indications of medications in use than the ones aged 60 to 69 years (5). This reaffirm the fact that medication knowledge among older patients is insufficient $(3,5-7)$, which may lead to medication nonadherence (6) and negative clinical implications (4). For instance, 75-year-old patients with adequate knowledge of the indications of the medications they used had 3.7 times more chance to follow the prescribed regimen than the ones with inadequate knowledge (6).

The aim of this study was to evaluate the knowledge octogenarian outpatients had about commonly prescribed

1. Department of Pharmacy, Faculty of Pharmaceutical Sciences, University of Sao Paulo, Sao Paulo, Brazil; 2. Department of Biological Sciences, Institute of Environmental, Chemical and Pharmaceutical Sciences, Federal University of Sao Paulo, Diadema, Brazil; 3. University Hospital, University of Sao Paulo, Sao Paulo, Brazil

Corresponding Author: Thiago Vinicius Nadaleto Didone, Department of Pharmacy, Faculty of Pharmaceutical Sciences, University of Sao Paulo, Sao Paulo, Brazil, E-mail: tdidone@gmail.com, Phone: 55-11-3091-9246, Fax: 55-11-3091-9283 medications.

\section{Methods}

Patients seen at the outpatient geriatric clinic of the University of Sao Paulo Hospital (São Paulo, Brazil) and having a valid prescription of at least one medication were included at random from March 2013 to February 2014. Patients having communication difficulties or not willing to be interviewed were excluded.

Patients were interviewed face-to-face in order to identify the prescribed medications in last geriatrician appointment and their Anatomical Therapeutic Chemical (ATC) codes (www.whocc.no), time of use, and knowledge. In the case of patients with dementia, we interviewed his/her caregiver responsible by the home organization of medications instead. We allowed interviewees to read the prescription if they felt the need to.

Medication knowledge is the knowledge needed to ensure the appropriate use of the medication. It was obtained for each medication by means of an 11-question Spanish questionnaire cross-culturally adapted into Brazilian Portuguese (8). Each question inquires the interviewee about one item of information on medication. We selected six questions, each one concerning one of the following items: dosage, form of administration, indication, storage, side effects, and precautions and warnings. Answers were classified either correct, incomplete, unknown or incorrect according to 
Table 1

Frequency of medications whose information was appropriately recalled

\begin{tabular}{|c|c|c|c|c|c|c|}
\hline Item of information & D & FA & I & $S$ & SE & PW \\
\hline \multicolumn{7}{|l|}{ Medication (ATC code) } \\
\hline acetylsalicylic acid (B01AC06) & $91 \%$ & $94 \%$ & $79 \%$ & $35 \%$ & $6 \%$ & $0 \%$ \\
\hline alendronic acid (M05BA04) & $36 \%$ & $36 \%$ & $18 \%$ & $9 \%$ & $0 \%$ & $0 \%$ \\
\hline amlodipine (C08CA01) & $79 \%$ & $79 \%$ & $53 \%$ & $37 \%$ & $0 \%$ & $0 \%$ \\
\hline atenolol (C07AB03) & $72 \%$ & $83 \%$ & $56 \%$ & $28 \%$ & $6 \%$ & $0 \%$ \\
\hline calcium carbonate/vit. D (A12AX) & $85 \%$ & $85 \%$ & $77 \%$ & $46 \%$ & $0 \%$ & $0 \%$ \\
\hline captopril (C09AA01) & $100 \%$ & $90 \%$ & $90 \%$ & $60 \%$ & $0 \%$ & $10 \%$ \\
\hline vit. D (A11CC05) & $76 \%$ & $76 \%$ & $47 \%$ & $53 \%$ & $0 \%$ & $0 \%$ \\
\hline vit. D/vit. A (A11CB) & $80 \%$ & $80 \%$ & $60 \%$ & $20 \%$ & $0 \%$ & $0 \%$ \\
\hline diltiazem (C08DB01) & $88 \%$ & $88 \%$ & $50 \%$ & $25 \%$ & $13 \%$ & $0 \%$ \\
\hline donepezil (N06DA02) & $88 \%$ & $100 \%$ & $63 \%$ & $50 \%$ & $25 \%$ & $0 \%$ \\
\hline enalapril (C09AA02) & $96 \%$ & $96 \%$ & $88 \%$ & $42 \%$ & $4 \%$ & $0 \%$ \\
\hline furosemide (C03CA01) & $77 \%$ & $85 \%$ & $62 \%$ & $38 \%$ & $8 \%$ & $0 \%$ \\
\hline hydrochlorothiazide (C03AA03) & $92 \%$ & $92 \%$ & $75 \%$ & $42 \%$ & $8 \%$ & $0 \%$ \\
\hline levothyroxine sodium (H03AA01) & $73 \%$ & $73 \%$ & $73 \%$ & $20 \%$ & $0 \%$ & $0 \%$ \\
\hline losartan (C09CA01) & $89 \%$ & $89 \%$ & $61 \%$ & $28 \%$ & $6 \%$ & $0 \%$ \\
\hline metformin (A10BA02) & $81 \%$ & $88 \%$ & $63 \%$ & $31 \%$ & $13 \%$ & $0 \%$ \\
\hline omeprazole (A02BC01) & $100 \%$ & $100 \%$ & $83 \%$ & $45 \%$ & $3 \%$ & $0 \%$ \\
\hline sertraline (N06AB06) & $100 \%$ & $100 \%$ & $50 \%$ & $63 \%$ & $0 \%$ & $0 \%$ \\
\hline simvastatin (C10AA01) & $91 \%$ & $91 \%$ & $55 \%$ & $45 \%$ & $5 \%$ & $0 \%$ \\
\hline
\end{tabular}

It was considered the 19 most commonly prescribed medications and 6 information needed for appropriate use of medications. D: dosage; FA: form of administration; I: indication; S: storage; SE: side effects; PW: precautions and warnings.

its degree of agreement with the UpToDate® database (www.uptodate.com). Two interviewers independently classified the answers and a third one was consulted if necessary.

Knowledge was expressed as the appropriate recall of the items mentioned above, that is when answers were either correct or incomplete (5). We analyzed only medications prescribed to $\geq 10 \%$ of patients. For every one of them, we calculated the frequency of medications appropriately recalled.

\section{Results}

We interviewed 80 individuals. There were 19 ATC 5th codes prescribed to $\geq 10 \%$ of patients, which corresponded to $61.5 \%$ (305/496) of all medications prescribed. Acetylsalicylic acid was the most prescribed medication ( $43 \%$ of patients) followed by omeprazole $(36 \%)$ and enalapril (30\%). Regarding the time of use, $72.5 \%(221 / 305)$ of the most prescribed medications were being used for more than 6 months. The majority (9/19) of medications acts on the cardiovascular system (ATC 1st code: C). The second most common (5/19) ATC 1st code was A (medications acting on the alimentary tract and metabolism).

Table 1 shows the frequency of medications whose information about dosage, form of administration, indication, storage, side effects, and precautions and warnings was appropriately recalled. Frequencies of these six items of information respectively ranged from $36 \%$ to $100 \%, 36 \%$ to $100 \%, 18 \%$ to $90 \%, 9 \%$ to $63 \%, 0$ to $25 \%$, and 0 to $10 \%$. The overall knowledge was intermediate to high regarding information on dosage and form of administration, varied a lot for information on indication and storage, and for information on side effects and precautions and warnings was almost non-existent.

Of note, the lowest appropriate recall of dosage and form of administration was found for alendronic acid. Still, the highest appropriate recall of side effects was seen for donepezil.

\section{Discussion}

A few Brazilian studies (9-11) corroborate our findings in spite of having evaluated only one prescribed medication and having had no constraints of age. For 
instance, in Grão Pará, Santa Catarina, 95.7\%, 60.0\%, $11.4 \%$, and 0 of primary care outpatients had appropriate knowledge of indication, dosage, precautions and warnings, and side effects, respectively (9).

Patients often demonstrate appropriate knowledge of how much to take of a medication and how to take it, since this information is usually present in prescriptions and constantly required when long-term medications are being used $(9,10)$. Here, the vast majority of medications has been prescribed for more than 6 months, which might have influenced the high frequencies of appropriate recall of dosage and form of administration. The latter can be explained by the simple instructions usually recommended in order to take oral products in safety (eg. taking with water was an answer good enough to be considered correct). Taking alendronic acid in safety needs more complex directions though. We believe the low appropriate recall of form of administration of alendronic acid resulted from insufficient counselling on this issue by healthcare professionals. In a 3-year trial there was no difference in the incidence of esophageal adverse reactions among individuals receiving placebo, 5,10 , or $20 \mathrm{mg}$ of alendronic acid because they were regularly seeing the physician who reinforced the instructions for the safe use of the medication in every encounter (12).

Although the frequencies of appropriate recall of indication varied widely among medications, the ones for the cardiac medications (ATC 1st code: C) are in line with a Dutch study, which showed that $61.6 \%$ of these medications were appropriately recalled by older primary care patients (5). Knowing the indication might be challenging when medications have multiple indications (eg. sertraline), were prescribed to prevent a condition rather than treat one (eg. acetylsalicylic acid) or in an irrational way (eg. omeprazole is not indicated to treat polypharmacy). In addition, this knowledge may be influenced by the amount of time of medication use and the skills needed to use it $(5,10)$.

Appropriate recall of storage was $\leq 50 \%$ for 16 out of 19 medications, indicating that most of them might have been inadequately stored. This is associated with patients' age and habits. In Cuité, Northeast Brazil, for example, 203 out of $267(76.0 \%)$ households had medications inadequately stored. Besides, the older the organizer of home medications, the higher the risk of them being inadequately stored (13).

The low frequencies of appropriate recall of side effects and precautions and warnings we found is ordinary. Safety issues are the least known information about medication in older individuals $(6,7,14)$. Reasons include not experiencing adverse reactions (10) and lack of counselling by healthcare professionals $(7,9)$ who fear nocebo effect or medication discontinuation (9). While $72.2 \%$ and $70.1 \%$ of older outpatients using long-term medications reported receiving information about the form of administration and the indication, $73.0 \%$ claimed that they did not receive any information on side effects
(14).

Since it is a first-line treatment for Alzheimer's disease, answers regarding donepezil information were given by caregivers instead of patients. Not surprisingly, they possessed the highest knowledge of side effects as caregivers of dementia patients actively seek key information about medications in use by their carerecipients, especially information on adverse reactions (15).

The lack of knowledge needed for appropriate use of medications may cause negative and significant clinical consequence. Not knowing information about dosage and form of administration may expose patients to adverse events and other risks of not following the prescription. The knowledge of indication may help patients assess the correspondence between indication and treating condition so that they can verify the clinical reasoning of the prescriber. In addition, not knowing storage information increases the odds of consuming badly preserved medications. Besides, patients who has appropriate knowledge of side effects may engage in preventive health behaviors and seek assistance to manage them when they manifest (14). Therefore, healthcare professionals must unquestionably provide reliable written and oral information on medication to patients and caregivers in order to increase their medication knowledge.

Selection bias may arise due to the inclusion not at random of individuals and the exclusion of the ones not willing to participate (eg. patients with gait disorders, caregivers late for work). Besides, it is expected that caregivers possess more medication knowledge than their care-recipients simply due to sociodemographic differences (eg. caregivers are usually women, younger and more educated).

Funding: TVND was granted with a fellowship by Conselho Nacional de Desenvolvimento Científico e Tecnológico - Brasil (CNPq), number 135839/20122. $\mathrm{CNPq}$ had no role in the design and conduct of the study; in the collection, analysis, and interpretation of data; in the preparation of the manuscript; or in the review or approval of the manuscript.

\section{Acknowledgements: None.}

Conflict of interest disclosure: TVND, DOM and ER have nothing to disclose.

Ethical standard: The study was performed in accordance with the ethical standards as laid down in the 1964 Declaration of Helsinki and its later amendments. The research ethics committee of the University of Sao Paulo (USP) Hospital and the Faculty of Pharmaceutical Sciences of the USP approved the study and all participants gave written informed consent to take part.

\section{References}

1. Eendebak R, Organization WH. World Report on Ageing and Health. 2015. Global: World Health Organization, Luxembourg.

2. Instituto Brasileiro de Geografia e Estatística. Projeção da população do Brasil e das Unidades da Federação [Internet]. 2019 [cited 2019 Jun 18]. Available from: https: / / www.ibge.gov.br/apps/populacao/projecao/.

3. Hartholt KA, Val JJ, Looman CW, Petrovic M, Schakel A, van der Cammen TJ Better drug knowledge with fewer drugs, both in the young and the old. Acta Clin Belg 2011; 66:367-370.

4. Tang EO, Lai CS, Lee KK, Wong RS, Cheng G, Chan TY. Relationship between patients' warfarin knowledge and anticoagulation control. Ann Pharmacother 2003; 37:34-39. 
5. Bosch-Lenders D, Maessen DW, Stoffers HE, Knottnerus JA, Winkens B, van den Akker M. Factors associated with appropriate knowledge of the indications for prescribed drugs among community-dwelling older patients with polypharmacy. Age Ageing 2016; 45:402-408.

6. Barat I, Andreasen F, Damsgaard EMS. Drug therapy in the elderly: What doctors believe and patients actually do. Br J Clin Pharmacol 2001; 51(6):615622.

7. Si P, Koob KN, Poonb D, Chew L. Knowledge of prescription medications among cancer patients aged 65 years and above. J Geriatr Oncol 2012; 3:123130.

8. Didone TVN, García-Delgado P, Melo DO, Romano-Lieber NS, MartínezMartínez F, Ribeiro E. Validação do questionário "Conocimiento del Paciente sobre sus Medicamentos" (CPM-ES-ES). Cien Saude Colet 2019; 24(9):35393550 .

9. Oenning D, Oliveira BV de, Blatt CR. Conhecimento dos pacientes sobre os medicamentos prescritos após consulta médica e dispensação. Cien Saude Colet 2011; 16(7):3277-3283.

10. Fröhlich SE, Dal Pizzol T da S, Mengue SS. Instrument to evaluate the level of knowledge about prescription in primary care. Rev Saude Publica 2010;
44(6):1046-1054.

11. Silva T, Schenkel EP, Mengue SS. Nível de informação a respeito de medicamentos prescritos a pacientes ambulatoriais de hospital universitário. Cad Saude Publica 2000; 16(2):449-455.

12. Liberman UA, Weiss SR, Bröll J, et al. Effect of oral alendronate on bone mineral density and the incidence of fractures in postmenopausal osteoporosis. The Alendronate Phase III Osteoporosis Treatment Study Group. N Engl J Med 1995; 333(22):1437-1443.

13. Martins RR, Farias AD, Oliveira YMDC, Diniz RDS, Oliveira AG. Prevalence and risk factors of inadequate medicine home storage: a community-based study. Rev Saude Publica 2017; 51:95.

14. Chan FW, Wong FY, So WY, Kung K, Wong CK. How much do elders with chronic conditions know about their medications? BMC Geriatr 2013; 13:59.

15. Aston L, Hilton A, Moutela T, Shaw R, Maidment I. Exploring the evidence base for how people with dementia and their informal carers manage their medication in the community: a mixed studies review. BMC Geriatr 2017; $17(1): 242$. 